\title{
CONCEPTUAL NEW SERVICE DEVELOPMENT MODEL
}

\author{
Ilona Skačkauskiene் $\dot{1}^{1}$, Asta Radzevičiene் ${ }^{2}$, Povilas Švogžlys ${ }^{3}$ \\ Department of Management, Faculty of Business Management, Vilnius Gediminas Technical University, \\ Sauletekio al. 11, LT-10223, Vilnius, Lithuania

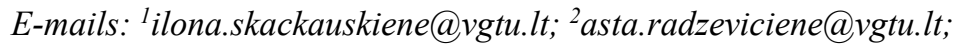 \\ 33povilas.svogzlys@vgtu.lt (corresponding author)
}

\begin{abstract}
In order to stand out in a competitive environment, companies are forced to consider the development of new services. In the context of globalization changes, the development of new services is becoming an effective tool for adapting to the changing needs of consumers through the introduction of technological innovations or management solutions. By using service development models, companies create favourable environment for generating and selecting ideas, and can prepare more effectively for the deployment of a new service. After the critical evaluation of the new service development models, conceptual new service development model was formulated. The indicators of conceptual new service development model were presented, also the unique features were highlighted. The results of this research revealed that new service development models are perceived as an unbroken cycle, that includes additional tasks for business subjects, consumers and company employees.
\end{abstract}

Keywords: service, service development, service ideas, conceptual model, critical evaluation.

JEL Classification: L81; L84; L86; L89.

\section{Introduction}

The service business can be called an important structural element, which provides a beneficial environment for economic development, general financial stability and attracts international investment as well. Global practice shows that potential investors are more likely to start a business in the service sector due to lower investments are needed. According to the data of the World Bank (2015), the global service sector generates $69 \%$ of the GDP. Furthermore, the industry of services generates the largest number of jobs in the well developed countries: in Luxembourg 89\%; in Hong Kong 85\%; in Singapore 83\%; in the Netherlands $82 \%$; in the USA $81 \%$; in Sweden $80 \%$; in the UK $-81 \%$; in Norway $78 \%$ and in Finland 74\% (World Bank 2017).

In the context of globalization, business subjects are no longer able to efficiently manage expenses, maintain quality of services or ensure loyalty of existing customers. The growing competition encourages all organizations to look for new ways of creating additional value. In order to be noticed in the competitive environment, the service businesses are forced not only to improve existing services, but also to create completely new ones, with the help of modeling services or other development models that are approved in practice.
Although the development of services is gaining more importance, the researchers have been analyzing it fragmentary, i.e. by researching the actions of the development of specific enterprises and the application of preventive measures. Moreover, there is no consensus on the elements of the models of the new services development, their interoperability or external interaction. Bullinger, Fahnrich, and Meiren (2003) points out that the structures and processes of current enterprises are not intended to effectively develop and start to provide services in the market.

The majority of new service development (further NSD) models do not provide any specific actions that must be adopted by the business subject after the service has been installed or delivered to customers. In the context of the constantly changing business environment, it is worthwhile to present the tasks that enable business entities to implement the key actions for the creation and development of a new service more effectively.

The goal of the research: to form a conceptual model for the new services development.

The tasks of the research: 1) to reveal the concept of the development of the service; 2) to analyze the development models and concepts of new services in the scientific literature; 3 ) to define the research space for new services and to 
form a conceptual model for the development of new services.

The research is based on systematic, comparative and critical analysis of the scientific literature, synthesis and modeling method.

\section{The concept of service development}

In the context of globalization, the precise definition of the term of a new service becomes one of the most complex theoretical tasks that researchers are facing: the changing needs of consumers and advanced technologies encourage the searches for the new outputs. Formerly, this term have been used to define only the creation of new services. However, in the modern business this term acquires a broader meaning. Before providing the definition of service development, it is necessary to analyse the scientific approaches to this process in the term of a new service of the modern researchers. According to Edvardsson and Olsson (1996), the new service depends on the current technical environment in many cases, when physical and technical resources can be different but stil match each other. In the opinion of the authors, it is extremely important to take into account the needs of staff and users. Tax and Stuart (1997) suggest to define the new services on the ground of the scale of the change in the existing service system or on the basis of the business process and the participants. The service concept represents the operational blueprint that communicates to customers and employees what they should expect to receive and to give (J. A. Fitzsimmons \& M. J. Fitzsimmons, 2001). According to Shostack (1987) and Johnston (1999), a new service is an interaction between participants, processes, and the series of the physical elements. Johnson, Menor, Roth, and Chase (2000) classifies them into the six main groups:

1. Major innovations - new services for markets as yet undefined. All the innovations usually are driven by information and computer-based technologies.

2. Start-up business.

3. New services for market presently served - new service offerings to existing customers of an organization.

4. Service line extensions - augmentations of the existing service line such as adding new menu items, new bus routes and etc.

5. Service improvements - changes in features of services that currently are being offered.
6. Style changes - slight changes in service structure.

Menor, Tatikonda, and Sampson (2002) quoting Menor (2000) defines a new service as an offering not previously available to customers resulting from the addition of a service offering or changes in the service concept that allow for the service offering to be made available. Sometimes new services are identified as service innovations. Defining innovation in the form of economic value for the developer provides a limited view of what an innovation is. Even if a new service creates significant benefits for customers, the service might not generate revenue to the developer (Witell, Snyder, Gustafsson, \& Fombelle, 2016). From the perspective of new services, Santamaría, Nieto, and Miles (2012) defines new service innovation as new services which have been introduced into the market, or existing services which have been significantly improved or important changes have been made to their basic characteristics, intangible components or desired purpose. After analyzing the attitudes of researchers to the concept of a new service, one can see some of the dominant characteristics: 1) the highlighting of the stuff and consumer aspect - the need to take into account their needs or the opportunity to integrate into the overall process of creating a new service; 2 ) the aspect of external and internal processes is distinguished that allows us to look at the new service from a systematic point of view. In sum up, the new service is a new proposal formed by a business entity due to the changing consumer needs, technological solutions or changes in a competitive market.

Providing the exact definition of the NSD is not easy due to the versatility of this term. The terminological variations can be found in the scientific literature: new service creation (NSC), service co-creation, new service development (NSD), service design and even the service innovations. The Service Design Network (2017) states that service development is essential point for all private and public organizations that want to innovate and improve their service strategies or offers to consumers. Stickdorn and Schneider (2012) point out that in a meantime of developing services, new or improved existing services are introduced in order to make them more useful or efficient, and meet the needs of modern customers. Smith and Fischbacher (2005) argue that the new services development involves the development of tangible and intangible elements of the service that were not previously offered by the provider. 
Many authors draw the attention to the relationship between the consumer and the business while talking about the development of new services. Moritz (2010) points out that the development of new services is a process focused on the creation of the added value for both players of the market. Erlhoff and Marshall (2008) follow a similar position by claiming that this process is intended to create a service that is in the best interest of the client and the business entity that provides it. Meanwhile, Aurich, Mannweiler, \& Schweitzer (2010) uphold the view that development of new services is a process of planning the components of human recourses, technologies and materials, in order to improve the quality of interaction between customers and service providers. Authors point out that choosing the right method for a NSD can improve the satisfaction of customers, as well as improve the efficiency of the company.

The NSD is identified as a set of tools or solutions in the scientific literature. Santos and Spring (2013) describe this process as the way in which activities and solutions are designed to analyse the market, develop a service concept or service. Meanwhile, Cambridge Service Alliance (2017) claims that the development of new services is the usage of methods and tools for developing new service systems or service activities with a special focus on the perception of quality, satisfaction and experience. Murthy, Rausand, and Osteras (2008) identifies goods and services with the same definition as products. The authors rephrase the definition of the Product Development and Management Association of USA point out that the development of a new product is a balanced set of tasks and steps that turn the company into sales of goods and services. A similar opinion is provided by Riedl, Leimeister, and Krcmar (2010). According to the author, the development of new services is a rather effective method that describes the main processes and tasks. Depending on the approaches of researchers, it can be said that the development of the new services let us not only to implement a service, but also to accomplish the complex tasks that are important to the activities of any organization.

Business Innovation Observatory (2015), by defining the new services development as a creative consumer-oriented design process, points out that it is a particularly valuable competitive advantage for creating the added value. Mayou (2017) has the similar attitude and sees the development of a new service as a customer-centric process when the creative solutions are used to eliminate disadvantages caused by the service business while improving the existing services or introducing the new ones.

The comparative analysis has revealed that theoretical complexity of the development of new services is determined not only by the width of the concepts, but by the frequently variations of this term found in scientific literature as well. Stickdorn and Schneider (2012) claim that the approach to service development is still evolving. It is noticeable that the definition of service development is gaining much broader significance in the context of globalization processes. The theoretical approaches to this process reflect: 1) the relationship between the client and the consumer; 2) highlight the importance of the aim; 3) identify the specific stages of the process. The results of the analysis showed that the development of services can be oriented towards the introduction of new services or the improvement of the existing ones. The factors, such as consumer behaviour or technological innovation, can encourage the subjects of the business to take the clearly measurable and competitive solutions that will enable the service to be developed more efficiently.

Taking into account all these mentioned scientific views, it can be claimed that the development of the new service should be considered as a necessary strategic solution and systematically evaluated by this process. Therefore, it is suggested that NSD can be defined as a multiple, customer-oriented process, during which managerial decisions are applied to the elimination of deficiencies in business, by improving existing ones or by introducing new services. This definition creates a good environment for the perception of the development of services from the perspective of a user and from the perspective of the organization as well, and let to search for the effective and optimal solutions in their provision.

\section{Critical evaluation of models of NSD}

The increasing competition encourage the service companies not only to take some actions to attract the potential customers, but also adopts specific solutions that allow them to continue the effectively development of a service package or to create new ways for new perspectives of development. New product development is one of the riskiest, but most critical strategies in any competitive industry (Cooper, 2001). Taking this view into account, the measures for development of a new service should effectively ensure the success of the implementation phase of each new service. 
The NSD models used to deploy the service can be identified as one of the major ways when it can be created or developed. The scientific literature present a number of the models for the service development that can all be categorized into the following groups according to the following qualifications:

1. Models with different structures of the process (cyclic or linear);

2. Models that distinguish additional business-oriented components (tasks, actions, additional activities);

3. Models that highlight the importance of engagement of the staff of the company (the aim of involving the largest possible number of employees in the creation of a new service);

4. Models that highlight the role of consumers and their ability to engage in the development of a service.

Usually, the models of a NSD attempt to highlight aspects related to the feasibility, quality assurance, commercialization, future development opportunities, or the relationship between the user and the business entity. A rather large variety of models raises additional questions for service companies about the choice of model, its effective application in practice, or the steps to be taken after a service is installed. It is not always clear whether the development of a new service should be completed at the stages of commercialization and deployment, or more attention should be paid for monitoring. In order to ensure the progress of service development models and their proper application for the customer needs of the customers, it is necessary to carry out a critical evaluation of the models of service development that are found in the scientific literature.

\subsection{The cyclic models of NSD}

Ideas, problems or scientific approaches related to the new services development in this kind of model are displayed during the formation of particular cycles. Cyclical model is presented by Bullinger and Schreiner (2006). The model consists of two cycles. The external circle consists of the main phases of the development of a new service, while the internal circle includes the tasks that should be taken in order to successfully implement the service: Start phase: 1) idea generation; 2) analytical phase: analysis of requirements, evaluation of ideas; 3 ) concept phase: compilation of individual specifications, compilation of overall specifications; 4) preparatory phase: provision of potencial; 5) test phase: testing of common specifications; 6) implementation phase: implementation of concept of the service.

The model can be applied not only for development of the new services, but for improvement of the previously installed services as well. According to the authors, each phase identified in the model can be evaluated in a non-ordered manner in the terms of the organization. However, each of them is still recommended to review.

By analyzing the importance of corporate resources for the development of new services, Froehle and Roth (2007) adapted a model for developing new services, which consists of two mutually functioning parts. The first part of this model consists of three factors that describe the resources of the company: intellectual, organizational and physical. In the second part of the model, the authors formed a NSD cycle consisting of four stages: design stage, analysis stage, development stage, launch stage. According to the authors, a resource-oriented model for development a new service enables to more effectively strengthen the abilities of the company in the context of the market, develop a package of services, as well as develop and motivate a team.

After the theoretical analysis, Kindström and Kowalkowski (2009) identified that most of the researches related to the development of new services are geared towards easy-to-access services available to consumers every day, and there is a gap between manufacturing companies that can offer service packages along with the goods they sell. In this context, the proposed cyclical model for service development is based on four interlinked phases: market sensing, development, sales and delivery. The authors emphasize that in every stage of this model the close communication and dialogue with the potential client is the key point.

Riedl et al. (2010) and Menor et al. (2002) analyzed a cyclical model for developing new services introduced by Johnson et al. (2000). This model consists of 4 separate stages: design, analysis, development and full launch. In each of these stages, the authors identified 12 individual tasks that the business might perform throughout the process in order to develop the successful service. In the inner part of the model, the authors distinguished three factors: organizational activity, team and tools. Each of these factors is responsible for utilizing different company resources for the development of a new service.

Santos and Spring (2013) present a conceptual model for developing a new service, in which 
the whole process takes place on a basis of the cycle. The model consists of three stages: emergence, accommodation, consolidation. The authors point out that the emergence stage as a reciprocal regulation between the provided services and the resources operated by the company. During the process of accommodation, a business entity can find out what is really going to be inside the company: new capabilities, technologies, or other equipment that matches the needs of a consumer. Meanwhile, the process of consolidation is achieved when the company understands the importance of the new service to the customer and define the structure of the process, i.e. activities, costs, capabilities and essential requirements. This conceptual model describes the process that occurs when providers of the service redistribute their operating resources and capabilities to implement the new services.

After analyzing the cyclical models, it is clear that most of them are formed in three or four stages. It can be claimed that by striving to compensate a smaller number of stages in the process of the development of a new service, the researchers identify the additional tasks that the business entity should take into account when designing and developing the service

\subsection{The linear models of NSD}

Although the early linear models had a rather simple structure, they are becoming increasingly complex in the modern context of the service sector and including not only the elements of the service, but also other components that affect the process.

Scheuing and Johnson (1989) formulated a structurally uncomplicated model for development of new service, which seeks to emphasize the interactions between each of the steps. Despite the fact that the model consists of up to fifteen stages, it does not include any identified additional tasks or intermediate teams that represent the purpose of development a service.

In order to investigate the aspects of the development of a new service in the financial sector, Alam and Perry (2002) presented a linear model made of 10 steps. In the intermediate elements of the model, authors depict the decision-making capabilities that a business can take in implementing the next go or no-go decisions. The model is also characterized by the fact that in each of these 10 steps, the authors point out the need for user engagement in the development of services.

After the conclusion that the involvement of staff in services is different in many organizations,
Shekar (2007) assessed the activities of New Zealand local authorities in developing services. Her conceptual model consists of nine stages and two interrelated parts. In the first part, she identified the early stages of the development of the service. The second part identifies late or otherwise called stages of service implementation. The conceptual model is distinguished by the fact that at each stage of the development of the service, individual roles of users or staff are highlighted. According to the author, this model is an instrument for supporting and improving the development of services.

Burger, Kim, and Meiren (2010) has formed a linear model for developing new services, which consists of six steps: idea management, requirements analysis, service design, service test, service implementation, market launch. Each of these phases includes the groups of individual tasks that the organization should take into account while developing a new service.

Lin and Hsieh (2011) noticed that there are not so much researches on the different stages of developing a new service. As a result, they decided to form a linear model based on the scientific approach based on the influence of these components on the development of services. The presented model consists of five interoperable phases: identification, value net formation, modeling, implementation and commercialization. In each of these phases, the authors have identified a few additional activities (tasks) that the business should accept in the process of developing a new service.

After analyzing the connections between designing and developing the service, $\mathrm{Yu}$ and Sangiorgi (2014) proposed a new model of the service development consisting of three parts:

- The objects. Contributing to a more efficient development of the concept of services and its delivery to the consumer, since here the focus is on developing user experience, ensuring the proper functioning of the entire service process and achieving the best result.

- The process. The development of the services is completely flexible and depends on the context of each project, but usually this process consists of 4 parallel stages: design, analysis, development, launch.

- The facilitators. These are auxiliary measures that aim to ensure the involvement of not only users but also the whole organization in the process of creating a new service. 
The first two fragments of the model are divided into half-way blocks. The subject of the business needs to answer two main questions here: "How the services are designed?" and "How the services implemented?" In the context of the development of the services, it can be stated that these questions make sense of the beginning and the end of the development of the service.

30 years ago it was difficult to find the right models of the service development that could reflect this whole process, but the modern literature offers the models of NSD that can be distinguished not only by their nature or number of stages but also by their specific features. In order to create a conceptual model for developing new services, it is necessary to refine the features and stages of such models found in the scientific literature (see Table 1).

The results of the comparative analysis reflect the widespread approach of the researchers to the development of new services. It has been noticed that the main stages in the models of the development of new services are considered as idea generation, analysis, service design, development and presentation of the service to the consumer. In addition to these stages, scientific literature can increasingly be seen in stages such as starting a strategy, testing a service, or implementing it. The main aspects of the benchmarking analysis can be distinguished as following:

- The importance of staff involvement. It is noticeable that the role of staff is increasingly highlighted in the development of new services. Involving employees in the development of the service makes it possible to generate and select ideas more efficiently and to stimulate the teamwork thus ensuring a better quality of service as well. According to Strazdas (2011), a diversified team has the direct and indirect impact on the success of the developing product.

- Usually, the stages of the models for the development of new service are added by the tasks that are addressed to business entities. It is noted that the authors try to compensate a smaller number of stages in the process of the development of a new service by additional tasks and means for the business entity.

- The role of the consumer. The essence of the provision of all services is focused on the client and satisfaction of his needs, therefore the main objective of the business is to provide a quality, innovative service that is consistent with the trends of nowadays. Naturally, the importance of the consumer can be seen in the newly formed models of new services development. Many authors distinguish the role of the consumer and its relationship with the service provider. According to Kiyak (2014), the universal engagement of the consumer in the process of provision of the service, the pricing process and the creation of perceived value necessitates the development of close and reliable customer relationships that leads to market orientation.

- No further stages of service management are distinguished. It has been determined that most of the models for the NSD are completed by Service Implementation or Service Launch phases. It presuppose that the additional tasks might be created, which would allow a business entity to administer the service more efficiently.

To sum up, the model of the NSD is a tool based on technical and managerial solutions for business entities to help create a new service or to improve the quality of the service already installed and its presentation to the user.

\section{The formation of the conceptual model for the NSD}

After the analysis of the interpretations of the models for the NSD that are described in the scientific literature, it might be claimed that mostly of these models are oriented to the development of services of a particular company, therefore, they generally do not possess universal features that could be adapted in the sector or individual market segments. It has been determined that the development of the new services are completed by service implementation or service launch phases, without distinguishing the specific actions and tasks that the business should pay attention to when the service is implemented. It can be assumed that without the monitoring solutions, created in the model of the new service, the business could have additional problems in the future:

- In the absence of feedback from the customers, the further development of the service may be disturbed.

- If the deficiencies would not be identified and eliminated after the implementation of the service, the general quality of the service may be decreased and, as a 
result, the business entity would lost its position in a competitive environment.

Taking into account the results of the analysis of the scientific literature and the different interpretations of the models of the NSD, a conceptual cyclic model for the development of new services is proposed (see Figure 1), which has several features that are not typical for such models:
1. When developing or improving services, time is becoming one of the most important factors affecting the efficiency and quality of this process. In the conceptual model for developing new services, there are 2 ways to reduce the duration of the creation process:

- The opportunity to overcome those stages where it is not expedient to perform the development of a service.

Table 1. The stages and features of NSD models (source: composed by the authors)

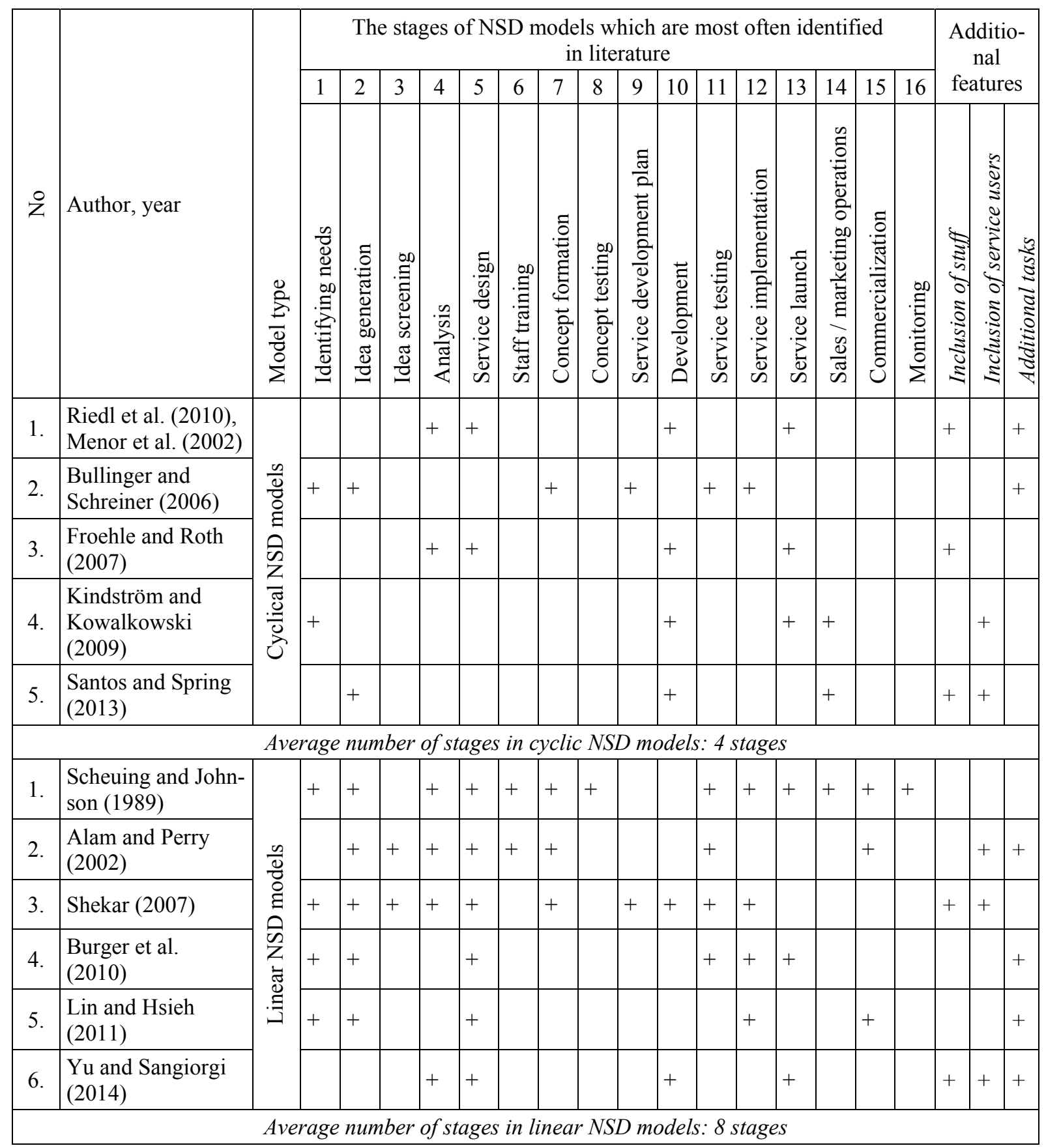




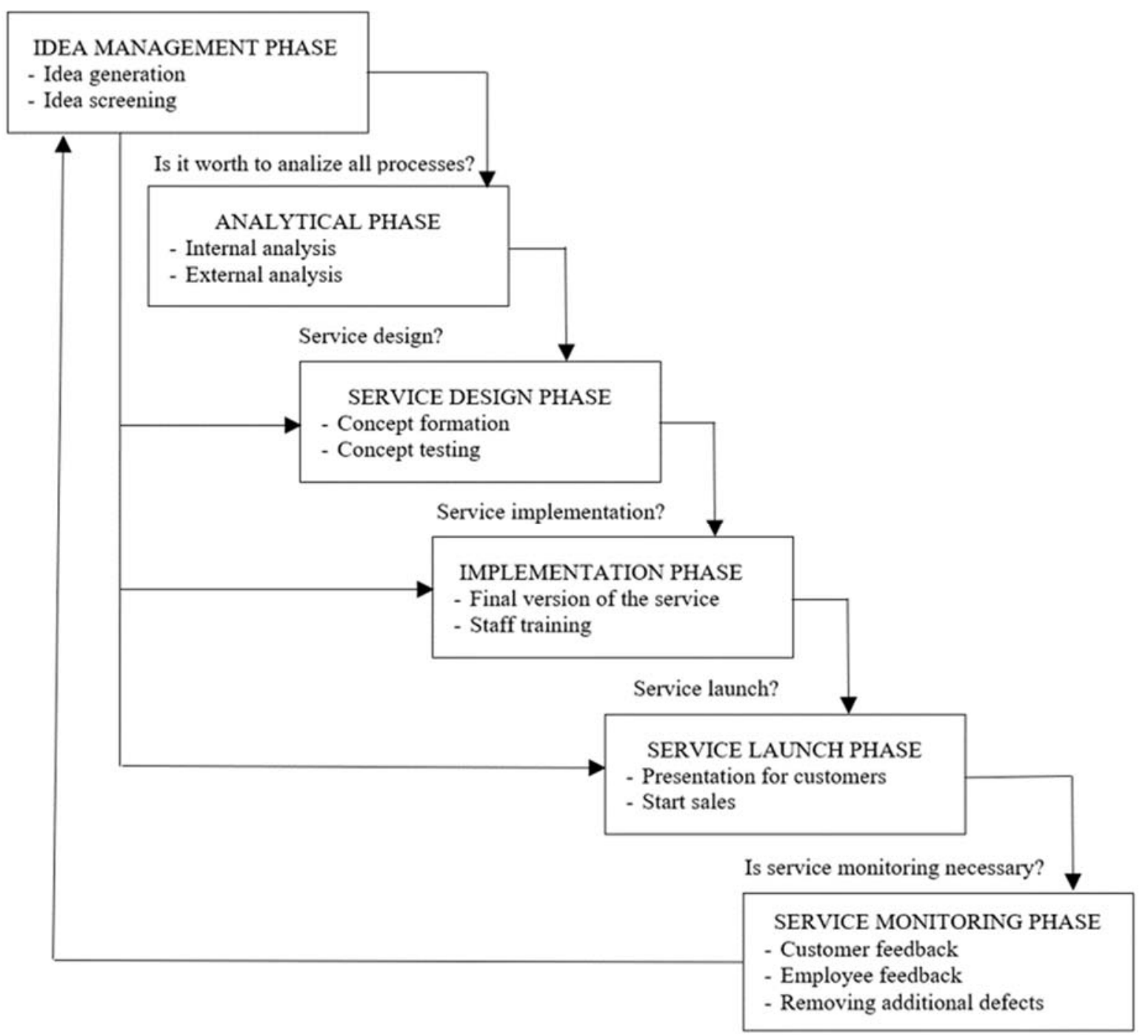

Figure 1. Conceptual NSD cyclic model (composed by the authors)

- Ability to create a service based on each stage of the NSD model.2. Considering that in most modern models of the NSD there are no identified stages when the business entity would be informed of the decisions to be made after the implementation of the service, this model distinguishes the service monitoring stage that includes the monitoring of the created services processes, elimination of deficiencies and ensures the maintenance of the relationship with the customers.

The conceptual new service development model has been developed based on the examples found in scientific literature. The number of model stages, complexion and their ranking have been chosen based on the results obtained in Table 1 .
In the phase of Idea Management of the proposed model, a business entity generates new service-oriented ideas, selects them (by eliminating the worst ones). At this stage, a business entity can involve both the customers by identifying their additional needs and company employees in order to generate the better quality of those service related ideas. In the phase of Analysis, the business performs external and internal analyzes related to the development of the new service. An external analysis involves collecting the information about potential competitors, as well as other data related to the creation of the service. The main aim is to identify the exceptional features of the service and the points that may attract the customers. In the course of internal analysis, the development of a new service is assessed from the perspective of the resources of the entity: is there the enough money, time and human resources to create and implement a new service. The qualification of a team 
that are working with a new service might be assessed as well in order to ensure the successful deployment of the service. In the phase of Service design, a business entity designs a new service. At this stage, the concept of the service is developed that later might be tested by the organization internally. The stuff and the potential customer might be involved in the design and testing of a new service. If the service produces the tangible results in the testing, the business entity might implement the service in the Implementation phase by creating a final, market-oriented service. The final version of the service is delivered to the customer in the Launch phase, when the campaign and sales might be started. Upon the implementation of the service, in the service Monitoring phase, the business entity might perform the further monitoring of the service and try to get comments, expectations and complaints from the customers and employees. The main disadvantages associated with the provision of the service might be eliminated and the further monitoring of the service might be done constantly.

Depending on the type of the service that was being developed, its complexity and the possibilities for the further development, the business entity can pass the stages of the analysis and monitoring. This can save the amount of time and money to improve other processes.

\section{Conclusions}

The results of the analysis revealed that the development of new services can be oriented towards the implementation of new services or the improvement of already existing ones. Thus, it can be assumed that this process is influenced not only by the factors such as consumer behavior or the development of technological innovations, but by the competition prevailing in the service sector as well. In summarizing the results of the theoretical analysis, it is proposed to describe the development of the new service as a multiple, customeroriented process, during which managerial decisions are applied to the elimination of deficiencies in business, by improving existing ones or by introducing new services. The proposed concept of the development of the new service makes it possible to evaluate this process from a systematic point of view. The proposed definition is universal as it covers a wide range of services: 1) services that involves the stuff in the development process; 2) services that involves the customers in the development process; 3 ) development of the complex and easy-to-use services; 4) development of the new services; 5) the improvement of the existing services.

The critical assessment of the models of the new service development has shown that this process is perceived as an unbroken cycle that includes additional variables: 1) the tasks, addressed to the business subject, are developing, complementing or, in some cases, changing the main stages of the new services development; 2) the models highlight the role of consumers and the need to involve them into the overall process of the development of a new service; 3) the importance of the stuff of a company is distinguished as it points out that an efficiently formed team can generate more qualitative ideas and make more measurable solutions.

In the scientific literature, the models are analyzing fragmentary. Although, in practice, the application of the models of the new services development has an impact on the efficient development of enterprise services, self-control or relationship with the customers and the staff. It can be claimed that the existing models tend to focus on the development of services in a particular enterprise, and therefore the lack of the flexibility to adapt it to the conditions of the sector or individual market segments is noticeable. Based on the results of the theoretical analysis, the conceptual model of the development of a new service was proposed. This model involves the new solutions that could facilitate the implementation of the service and its further development: 1) the ability to avoid the stages in which the development of the work is not purposive; 2) the ability to develop the service based on each stage of the service development model; 3) the service monitoring phase is distinguished that includes the monitoring of the process of the development a new service, elimination of the deficiencies and ensures the customer relationships maintenance.

\section{References}

Alam, I., \& Perry, C. (2002). A customer-oriented new services development process, Journal of Services Marketing, 16(6), 515-534.

https://doi.org/10.1108/08876040210443391

Aurich, C. J., Mannweiler, C., \& Schweitzer, E. (2010). How to design and offer services successfully, CIRP Journal of Manufacturing Science and Technology, 2(3), 136143. https://doi.org/10.1016/j.cirpj.2010.03.002

Bullinger, H. J., Fahnrich, K. P., \& Meiren, T. (2003). Service engineering - methodical development of new service products. International Journal of production Economics, 85(3), 275-287.

https://doi.org/10.1016/S0925-5273(03)00116-6 
Bullinger, H. J., \& Schreiner, P. (2006). Service Engineering: Ein Rahmenkonzept für die systematische Entwicklung von Dienstleistungen. Service Engineering. Heidelberg: Springer Verlag.

Burger, T., Kim, K., J., \& Meiren, T. (2010). A Structured test approach for service concepts. International Journal of Service Science, Management, Engineering, and Technology, 1(4), 12-21. https://doi.org/10.4018/jssmet.2010100102

Business Innovation Observatory. (2015). Design for Innovation: service design as a means to advance business models. Retrieved from https://ec.europa.eu/ docsroom/documents/13406/attachments/2/translations/en/renditions/pdf

Cambridge Service Alliance. (2017). Definitions of servicerelated terms. Retrieved from https://cambridgeservicealliance.eng.cam.ac.uk/Research/Glossary

Cooper, R. G. (2001). Winning at new products ( $3^{\text {rd }}$ ed.). New York: Addison Wesley.

Edvardsson, B., \& Olsson, J. (1996). Key koncepts for new service development. The Service Industries Journal, 16(2), 140-164. https://doi.org/10.1080/02642069600000019

Erlhoff, M., \& Marshall, T. (2008). Design dictionary. Basel: Springer Basel AG. https://doi.org/10.1007/978-3-7643-8140-0

Fitzsimmons, J. A., \& Fitzsimmons, M. J. (2001). Service management ( $3^{\text {rd }}$ ed.). McGraw-Hill, New York.

Froehle, M. C., \& Roth, V. A. (2007). A resource-process framework of new service development. Production and Operations Management, 16(2), 169-188. https://doi.org/10.1111/j.1937-5956.2007.tb00174.x

Johnson, S. P., Menor, L. J., Roth, A. V., \& Chase, R. B. (2000). A critical evaluation of the new service development process: integrating service innovation and service design. In J. A. Fitzsimmons, \& M. J. Fitzsimmons (Eds.), New service development - Creating memorable experiences. Sage Publications, Thousand Oaks. https://doi.org/10.4135/9781452205564.n1

Johnston, R. (1999). Service operations management: return to roots. International Journal of Operations and Production Management, 19(2), 104-124.

https://doi.org/10.1108/01443579910247383

Kindström, D., \& Kowalkowskic, C. (2009). Development of industrial service offerings: a process framework. Journal of Service Management, 20(2), 156-172. https://doi.org/10.1108/09564230910952753

Kiyak, D. (2014). Produkto vertès sampratos koncepcija, kainodaros procese. Regional Formation and Development Studies, 1(9), 79-92.

Lin, F., \& Hsieh, P. (2011). A SAT view on new service development. Service Science, 3(2), 141-157. https://doi.org/10.1287/serv.3.2.141

Mayou, G. (2017). Service design, a tale of two coffee shops. Retrieved from https://www.fjordnet.com/conversations/watch-service-design-a-tale-of-two-coffeeshops/

Menor, J. L., Tatikonda, V. M., \& Sampson, E. S. (2002). New service development: areas for exploitation and exploration. Journal of Operations Management, 20(2002), 135-157. https://doi.org/10.1016/S0272-6963(01)00091-2

Menor, L. J. (2000). An empirical investigation of new service development competence and performance $(\mathrm{PhD}$ Dissertation (unpublished)). University of North Carolina.
Moritz, S. (2010). Service design: practical access to an evolving field. Retrieved from http://www.servicedesignbooks.org/isbn/9781445206677/service-design/

Murthy, D. N. P., Rausand, M., \& Osteras, T. (2008). Product reliability: specification and performance. New York, NY: Springer US.

Riedl, C., Leimeister, J. M., \& Krcmar, H. (2010). Why e-Service development is different: A literature review. e-Service Journal, 8(1), 1-37.

Santamaría, L., Nieto, J. M., \& Miles, I. (2012). Service innovation in manufacturing firms: Evidence from Spain. Technovation, 32(2), 144-155. https://doi.org/10.1016/j.technovation.2011.08.006

Santos, B. J., \& Spring, M. (2013). New service development: managing the dynamic between services and operations resources. International Journal of Operations and Production Management, 33(7), 800-827. https://doi.org/10.1108/IJOPM-12-2012-0559

Scheuing, E. E., \& Johnson, E. M. (1989). A proposed model for new service development. Journal of Services Marketing, 3(2), 25-34. https://doi.org/10.1108/EUM0000000002484

Service Design Network. (2017). Service Design definition. Retrieved from https://www.service-design-network.org/manifesto

Shekar, A. (2007). An innovative model of service development: A process guide for service managers. The Innovation Journal: The Public Sector Innovation Journal, 12(1), 1-18.

Shostack, G. L. (1987). Service positioning through structural change. Journal of Marketing, 51(1), 33-43. https://doi.org/10.2307/1251142

Smith, M. A., \& Fishbacher, M. (2005). New service development: a stakeholder perspective. European Journal of Marketing, 39(9/10), 1025-1048. https://doi.org/10.1108/03090560510610707

Stickdorn, M., \& Schneider, J. (2012). This is service design thinking: basic, tools, cases. Netherlands: Bis Publishers.

Strazdas, R. (2011). Produkto inovacijų kūrimas kūrybinių industrijų įmonèse. Santalka: Filosofija, Kominikacija, 19(2), 17-28 https://doi.org/10.3846/coactivity.2011.11

Tax, S. S., \& Stuart, I. (1997). Designing and implementing new services: the challenges of integrating service systems. Journal of Retailing, 73(1), 105-134. https://doi.org/10.1016/S0022-4359(97)90017-8

Witell, L., Snyder, H., Gustafsson, A., \& Fombelle, W, P. (2016). Fefining service innovation. Journal of Business Research, 69(8), 1-11. https://doi.org/10.1016/j.jbusres.2015.12.055

World Bank. (2015). Services, etc., value added (\% of GDP). Retrieved from https://data.worldbank.org/indicator/NV.SRV.TETC.ZS

World Bank. (2017). Employment in Services (\% of total employment). Retrieved from https://data. worldbank.org/ indicator/SL.SRV.EMPL. ZS

Yu, E., \& Sangiorgi, D. (2014). Service design as an approach to new service development: reflections and future studies. In ServDes.2014 Service Future, Proceedings of the Fourth Service Design and Service Innovation Conference, 9-11 April 2014. Lancaster, United Kingdom. 